\title{
Arguing About The Kalam Cosmological Argument
}

William Lane Craig's defence of kalam cosmological arguments has generated a large amount of discussion in the years since the publication of his book on that topic. ${ }^{1}$ John Mackie $^{2}$, Quentin Smith ${ }^{3}$, Adolf Grunbaum ${ }^{4}$ and $\mathrm{I}^{5}$ are just some of the philosophers who have engaged in prolonged debates in the journals with Craig on issues which arise in connection with his defence of those arguments. Given the amount of discussion which has already taken place, one might be given to wonder whether there are any important points which remain to be made. Perhaps unsurprisingly, I think that it is clear that there are important issues which have not been taken up in the previous discussion; I propose to take up one such set of issues in this paper.

The main question I want to address here is this: Given that someone presents you with an argument for a given conclusion, under what conditions should the person who presents the argument be prepared to agree that the argument is unsuccessful? Ultimately, my aim is to argue that, in light of some of the criticisms which have been made in the literature, Craig ought to be prepared to concede that what he calls "the kalam cosmological argument” is plainly an unsuccessful argument. However, much of the paper is taken up with consideration of preliminary matters which need to be addressed in order to provide a satisfactory answer to the main question.

In a full discussion of this main question, one would need to provide: (a) an account of rationality and rational belief revision; (b) an account of arguments; (c) an account of rational argumentation amongst rational agents; and (d) a discussion of the problems which arise as a result of the fact that we are not perfectly rational agents. I shall say a little about each of these topics, though I recognise that what I have to say will not amount to a thorough discussion of any of them. I shall then go on to apply the results from this part of the paper to the on-going debate about kalam cosmological arguments. Finally, I shall discuss two cases-one from Craig's criticisms of Grunbaum (2000) and one from Craig's criticisms of Oppy (1995b) — which it seems to me that those criticisms turn on misunderstandings of the proper framework within which rational argument takes place.

It seems to me to be plausible to think that reasonable people can disagree. Indeed, it seems to me to be more or less platitudinous that there are propositions that $\mathrm{p}$ such that some reasonable people believe that $\mathrm{p}$, some reasonable people believe that not $\mathrm{p}$, and other reasonable people are agnostic or indifferent in one way or another. Moreover, it

\footnotetext{
${ }^{1}$ Craig (1979)

${ }^{2}$ Mackie (1982), Craig (1985)

${ }^{3}$ Smith (1987) (1988) (1991) (1993a) (1993b) (1993c), Craig (1988), (1991a) (1991b) (1992a) (1992b)

${ }^{4}$ Grunbaum (1990) (1991) (1994) (1996) (2000) (forthcoming), Craig (1992a) (1994a) (1994c)

${ }^{5}$ Oppy (1991) (1995a) (1995b) (1995c) (1996) (2001), Craig (1993a) (1997)
} 
would be wrong to think that, where there is disagreement about the truth of some proposition that $\mathrm{p}$, all but one of the parties to the disagreement must be manifesting irrationality with respect to the subject matter at hand. That is, it seems to me to be more or less platitudinous that there are propositions that $\mathrm{p}$ such that some reasonable people act reasonably in believing that $p$, other reasonable people act reasonably in believing that not $\mathrm{p}$, and other reasonable people act reasonably in being agnostic or indifferent in one way or another.

Of course, some of the actual disagreements between reasonable people can be traced to irrationalities: sometimes reasonable people do have 'blindspots' where irrationality creeps in. Moreover, there is a substantial body of psychological research which suggests that our 'reasonableness' is actually quite imperfect-i.e., even at the best of times, we are prone to all kinds of lapses from ideal rationality (especially when it comes to statistical and probabilistic reasoning). However, there are at least two other sources of disagreements between reasonable people which are equally significant. One is that we all have different bodies of evidence-we draw on different bodies of informationwhich we obtain in all manner of different ways. Even if-perhaps per impossible-we were perfectly rational, it would still be possible for us to disagree provided only that each of us had different partial bodies of evidence. Moreover, even if we were perfectly rational, and had accessed the same full body of evidence, it might still be possible for us to disagree provided that we accessed the evidence in differing orders (and provided that our finite capacities ensured that we could not 'store' - or access - the full body of evidence all at once). The other source of disagreement between reasonable people is that there is no one set of 'priors' which any reasonable person must have. Again-though I admit that this is slightly more controversial-it seems to me that, even if we were perfectly rational, it would be possible for us to disagree simply because we have differing 'priors' (and this would remain true even if we accessed the same full body of evidence in the same order). Of course, in saying this, I am not commiting myself to the claim that there are no substantive constraints on 'priors' - it may be that there are quite severe constraints on reasonable sets of 'priors'; however, I am claiming that I can see no reason at all for thinking that there is a unique set of 'priors' which any reasonable person must have on pain of conviction of irrationality.

The above remarks seem to me to fit naturally into a neo-Quinean picture of the web of belief. ${ }^{6}$ At any time, a person has a network of beliefs which are connected together in various ways. Under the impact of evidence, the person will be disposed to revise their beliefs in various ways. If they are rational, then they will be disposed to revise their beliefs in accordance with the canons of belief revision (whatever those happen to be-it is not part of my present brief to elaborate any substantial account of the content of those

\footnotetext{
${ }^{6}$ It is important to emphasise that the picture is only neo-Quinean. In particular, it should be stressed that the picture which I have sketched is not incompatible with the further claims that some beliefs are nonnegotiable and unrevisable, that some beliefs have contents which are analytic and true $a$ priori. Moreover, it is not incompatible with the suggestion that the canons of belief revision-or at least some aspects of those canons - and other framework features of the picture are also somehow a priori (e.g. because they are conceptual bedrock, or because there is some legitimate way in which they can be justified by selfapplication, or whatever). It would take us too far afield to try to investigate the question of just how Quinean the picture ought to be.
} 
canons). Perhaps, for any given reasonable person in any given state, there is a unique rational revision which they ought to make to their beliefs under the impact of a given piece of evidence; perhaps not. Even if there is a unique rational revision to be made (for any person in any state given any evidence), there is no reason to think that there is bound to be convergence of belief given similar (or identical) evidential inputs. (If there is no unique rational revision to be made in the envisaged circumstances, then the prospects for convergence are even dimmer. However, I am prepared to suppose that there are unique rational revisions.) I see no reason at all why it could not be that a single piece of evidence leads you to believe that $\mathrm{p}$ and me to believe that not $\mathrm{p}$, even though we both act with perfect rationality. And even if that claim is too strong, it seems pretty clear that what one ought to come to believe under the impact of any given evidence depends upon what one already believes.

My earlier talk about 'priors' was meant to suggest a Bayesian conception of belief revision. However, it was also intended to be deliberately ambiguous between 'prior probability' and 'prior belief'. It is a crucial part of the picture which I am sketching that all assessment of evidence takes place against an already existing background of beliefs, so that there can be no question of one's 'examining' all of one's beliefs at once. The crucial questions about reasonable belief revision thus turn out to be questions about coherence with beliefs that one already has. Moreover it seems psychologically reasonable to conjecture that there are bound to be 'environmental' influences on the network of beliefs which one comes to hold (one's belief system is in part caused by one's upbringing, etc.). However, there is no room for the thought that one might 'makeover' one's system of belief, throwing out those beliefs which have 'mere causes' and preserving those for which one has 'reasons' - for every belief stands or falls by coherence with the rest, and the environmental influences impact on the network as a whole. Of course, it could be that considerations of coherence lead you to revise families of belief-e.g. belief in Santa Claus ceases to cohere with the rest of a child's body of beliefs, and is replaced (in part) by beliefs about Santa Claus stories and the like-and that this process of revision leads one to hold that certain beliefs were merely 'caused''I only believed in Santa Claus because my parents inculcated the belief in me'. But this process of labelling can only proceed ex post facto-in order to judge that some of one's beliefs are 'merely caused', one must first decide to give them up. (There is a first person / third person asymmetry here: I may be perfectly well-entitled, or even obliged, to judge that some of your beliefs are 'merely caused', particularly if they manifest a sufficiently deeply rooted disagreement.)

Plainly, there is much more to be said about the nature of reasonable belief. However, the last remaining thing which will be important for what follows is to note that nothing in the account that I have given is inconsistent with the idea that the aim of belief is truth, and the further idea that truth is a non-epistemic, non-relative notion. Nor, indeed, is anything in this account inconsistent with the idea that justification and warrant can be external matters, i.e. matters which have more to do with how an agent is connected to the world than they have to do with how things are inside the agent's head. All that is being insisted on is that there is an important sense in which reasonable people must be amenable to reason, where "amenability to reason" is a matter of how things are inside 
the agent's head. If you are going to argue with someone-i.e. to present an argument to them, or to engage in genuine argument with them-then you need to suppose that they are reasonable in this sense; but it is perfectly consistent with this assumption of rationality that you suppose that many of that person's beliefs are not warranted or justified, let alone true, because they are not appropriately connected to how things are outside that person's head. (Of course, it is a controversial question whether we should be externalists about warrant and justification. I think that nothing in what follows turns on how we choose to answer that question; in any case, I do not propose to try to pursue that issue here.)

So far, I have been talking about reasonable belief and belief-revision. The next item of business is to say something about arguments and their role in belief revision.

I take it that the proper function of arguments is to bring about reasonable belief revision: the aim of my argument for the conclusion that $\mathrm{p}$ is to bring you to reasonable acceptance of that conclusion. Of course, there are all kinds of other things which can be done with arguments-I may seek to dazzle you with my brilliance, or entertain you with my logical facility, or ...-and there are all kinds of other ways in which I may try to bring you to (reasonable) acceptance of the conclusion that p-I may tell you a story which illustrates its truth, or show you some evidence, or ... . However, the crucial point is that the telos of argumentation is bound up with reasonable belief revision.

Given this much, what shall we take to be the characteristics of a good (or successful) argument? Perhaps this seems easy: a good argument is one which succeeds-or perhaps would or ought to succeed-in bringing about reasonable belief revision in reasonable targets. The most successful argument would be one which succeeds-or perhaps would or ought to succeed - in persuading any reasonable person to accept its conclusion; good, but less successful arguments would be ones which succeed - or perhaps would or ought to succeed-in persuading a non-zero percentage of reasonable people to accept their conclusions. However, as we shall now see, there are here many difficulties which lie just below the surface.

Some arguments — including the kalam cosmological argument which Craig defends —are deductively valid (or, in some cases, mistakenly supposed to be deductively valid). In this case, what the argument establishes - or purports to establish-is that it is a logical error to accept all of the premises of the argument, and yet to reject the conclusion of the argument: no reasonable person can accept all of the premises, and yet also reject the conclusion. Other arguments-including those which appear to rely upon induction, or inference to the best explanation, and the like-are typically not supposed to be deductively valid. In this case, what is typically supposed is that the argument establishes — or, at any rate, purports to establish — that it is reasonable-perhaps even most reasonable - to accept the conclusion of the argument on the basis of the premises. 
(If it is most reasonable to accept the conclusion on the basis of the premises, then it seems, again, that no reasonable person can accept all of the premises and yet also reject the conclusion.)

In both kinds of arguments, there are various kinds of things which can go wrong. For instance, in both kinds of cases, one can be mistaken about the kind of support which the premises actually lend to the conclusion. As we noted before, people are far from perfect performers of deductive reasoning, statistical reasoning, probabilistic reasoning, and the like. However, for present purposes, we can set these types of cases aside: the main kind of criticisms which people have wanted to make of Craig's kalam arguments are not of this kind. Given the telos of argumentation, there is another kind of difficulty which arises in the assessment of the merits of an argument, concerning the acceptability of the premises of the argument. If a reasonable person need not accept all of the premises of an argument, then that argument does not give all reasonable people a reason to accept its conclusion. If a reasonable person ought not to accept all of the premises of an argument, then that argument cannot give any reasonable people a reason to accept its conclusion. Hence, in determining the merit of an otherwise acceptable argument, we always need to ask whether reasonable people may, or must, accept all of the premises of the argument. If the argument has no premises - as may be the case, for example, in reductio arguments - then this is not a substantive requirement; otherwise it is.

Even if an argument is in good inferential standing and possessed of acceptable premises, there are still things which can go awry. In particular, arguments which are circular, or question-begging, or which presuppose what they are supposed to establish, or the like, are plainly not good arguments. No theist can suppose that the argument "God exists, therefore God exists", or the argument "Either 2+2=5 or God exists, It is not the case that $2+2=5$, therefore God exists”, is a good argument even though, in each case, the argument is classically valid and possessed of premises which the theist supposes to be true. Of course, it is not an easy matter to say exactly what the fault is which is intended to be picked out by the labels "circular", "question-begging”, "assumes what it sets out to prove”, and the like. However, I think that what I shall have to say in the next section will suffice for the purposes of the current paper.

There are many further questions about arguments which I have ducked in the forgoing discussion. In particular, it is worth noting that I haven't said anything about how arguments are identified, i.e. about the question of when we should say that we have two different arguments rather than one argument presented in two different forms. One difficulty here is that there are two quite different ways in which one might think about arguments. On the one hand, we might suppose that an argument is identified simply by a collection of propositions, one of which is identified as the conclusion of the argument, and the others of which are identified as the premises. On the other hand, we might think that an argument is identified by a particular derivation of a conclusion from a bunch of premises (so that there can be many arguments with the same premises and conclusions, but which rely on different rules of inference, and travel by different sequences of inferential steps). For present purposes, it seems to me that no harm can come from choosing to work with the first conception (particularly since, in the case of Craig's 
kalam cosmological argument, there is no controversy about how to get from the premises to the conclusion); moreover, I think that this is the way in which those who discuss arguments about the existence of God typically think about the identity conditions for arguments. One importance consequence to note is that, where subsidiary arguments for premises in a target argument are introduced, what happens is that a new argumentwith different premises - is then brought up for consideration. In general, the move of introducing supporting arguments is a tacit concession that the original argument was not successful.

With these preliminary considerations about rational belief and argument in place, we can now turn to questions about the characterisation of rational argumentative interchanges between rational agents.

Suppose that a rational agent A wants to bring a rational agent B to accept the proposition that $\mathrm{p}$. There are two cases to consider. First, it might be the case that $\mathrm{B}$ has no opinion about whether that $\mathrm{p}$ (and even, perhaps, holds no beliefs which are relevant to that question). In that case, any good argument-i.e. any argument in which there is sufficient genuine transmission of truth or acceptability from premises to conclusion-which takes as premises things which $\mathrm{B}$ already accepts - at least once the premises have been propounded-will be an argument which succeeds in giving $B$ a reason to accept the conclusion that $\mathrm{p}$ (and will lead to B's acquisition of a suitable family of beliefs). Moreover, any argument which fails to have the properties just adverted to-i.e. any argument which is not good, or which proceeds from premises which B does not accept-will not be an argument which succeeds in giving B a reason to accept the conclusion that $\mathrm{p}$. To repeat this last point: an argument which takes as premises propositions which those to whom the argument is directed do not accept is a failure, and those to whom it is directed are perfectly correct in saying so.

Second, it might be the case that $\mathrm{B}$ has already considered the question whether $\mathrm{p}$, and that $\mathrm{B}$ either rejects the claim that $\mathrm{p}$, or else that $\mathrm{B}$ suspends judgment about this matter. In either case, given the presumed rationality of $\mathrm{B}$, it is bound to be the case that $\mathrm{B}$ has numerous related beliefs which support either the rejection of that claim that $\mathrm{p}$ or the suspension of judgment about whether $\mathrm{p}$. So, in this case, what is going to be required, in order to persuade B that p, is a good argument-i.e. an argument in which there is sufficient genuine transmission of truth or acceptability from premises to conclusionwhich takes as premises things which B believes, and to which B is more strongly committed than B is to the previously mentioned supporting beliefs. (Of course, as in the previous case, these premises can appeal to things which $\mathrm{B}$ has not hitherto considered, provided that $B$ is then disposed to accept them.) When presented with an argument which meets these requirements, B will undergo a revision of beliefs in such a way as to take on the belief that p, and various other beliefs as well. Again, as in the first case, an argument which fails to have all of the properties adverted to-i.e. an argument which is not good, or which proceeds from premises which B does not accept, or which proceeds 
from premises to which B is less strongly attached than B is to beliefs which support either rejection of the claim that $\mathrm{p}$ or else suspension of judgment whether $\mathrm{p}$ - simply fails to be an argument which gives $\mathrm{B}$ reason to accept the conclusion that $\mathrm{p}$.

It is a consequence of the above discussion that it is not easy for one rational person to persuade another rational person who already holds an opinion on a given matter to revise that opinion. Of course, if the proponent of the argument has new evidence which is produced in the course of the argument—and if it is reasonable for the target of the argument to accept that it is new evidence-then persuasion to change of view can be relatively straightforward. But, in that kind of case, it is the acquisition of the new evidence which is really doing all of the important work: a perfectly rational agent would only need to be presented with the new evidence-without the supporting argumentative dress - in order to be led to make the appropriate revisions in belief. And, in cases where there is no new evidence in the premises, it is almost impossible for an argument to be successful, at least in the case of perfectly rational agents. Where agents are less than perfectly rational, it may be that there are unnoticed implications of beliefs which, once drawn to their attention, will lead them to belief revision of a desired kind; but a successful argument for the claim that $\mathrm{p}$ must be one which leads to adoption of the belief that $\mathrm{p}$, and not merely to some revision or other in the beliefs of the target of the argument. I think that these consequences of the above account are not unwelcome; it is a commonplace that philosophers almost never change their beliefs about important propositions as a result of the arguments of others, even though the behaviour of philosophers with respect to these beliefs is about as rational as human behaviour ever gets to be.

Of course, the account of argumentation in the previous section was all based on the assumption that the agents involved are rational. However, as I noted in the first section of the paper, people are less than rational at least some of the time, and so there are questions about how to extend the account so that it applies to actual cases. At least sometimes, people who refuse to accept the conclusion of an argument which is presented to them are merely manifesting irrationality; so a measure of the worth of an argument can't be taken directly from the rate of success which the argument has in persuading those who did not previously accept the conclusion of the argument to change their minds. Nonetheless, it is surely the case that, if there are many people who do not accept the claim that $\mathrm{p}$, and if almost none of those people are persuaded to change their mind when presented with a given argument for the conclusion that $\mathrm{p}$, then it would take an enormously strong supporting argument-concerning the lack of rationality of all of those people-in order to overthrow the conclusion that the argument in question is plainly no good.

We can also think about these matters in the following way. Suppose that someone-A, say-wishes to persuade other people to accept the conclusion that p. A has an argument which is presented to some people who do not accept the conclusion that $\mathrm{p}$, and the argument turns out to be entirely unsuccessful: none of the people in question is 
persuaded to take on the belief that $\mathrm{p}$ as a result of hearing the argument. A has two options: either A can conclude that the people in question are not rational; or else A can conclude that the argument is a failure. If A concludes that the people in question are not rational, then there is no point in persisting with the attempt to champion any argument for the conclusion that p. (If A supposes that people who do not believe that $\mathrm{p}$ are, ipso facto, irrational — and, in particular, that such people are ipso facto irrational when it comes to the question of whether that $\mathrm{p}$ - then it is a pointless and empty performance to go on producing arguments with the conclusion that $\mathrm{p}$, since there is no possible target for those arguments.) On the other hand, if A concludes that the argument is a failure, then it is up to A to look for a new argument for the conclusion that p, or to give up on the attempt to use arguments to persuade others to accept the conclusion that p; but what $\mathrm{A}$ cannot do is to go on insisting that the argument in question is a good one.

Perhaps it might be replied that the above discussion makes the mistake of assuming that there is only one thing which arguments are for. Sure, an argument for the conclusion that $p$ which does not meet the exacting standards described will not—and ought not to-be able to persuade people to change their minds about whether that p; but that doesn't mean that it might not have some other use. Such as? Well, one thing that many so-called arguments do is to exhibit logical relations between propositions; surely it can be useful to exhibit justificatory relations between beliefs, in order to improve our systems of belief. (Think, for example, of the role which systematic proof plays in mathematics. Many of these proofs are plainly not designed in order to persuade cognisers of the proofs of the truth of their conclusions.) Perhaps this point can be conceded in general; however, it seems to me that argument in philosophy_and, in particular, arguments about the existence of God-almost never have this kind of rationale. If we ask about what really plays the role of justifying belief in God in typical believers, we can be quite sure that it is almost never the implicational relations which hold between the proposition that God exists and the kinds of propositions which turn up as premises in standard arguments for the existence of God. While there is more to be said on this issue, I think that it is pretty clear that this suggestion about a different use for arguments won't apply in the case in which we are interested; and more generally, I think that it is actually pretty hard to think of anything else which arguments are for. ${ }^{7}$ While noting that there is room for further thought on this matter, I think that there is good reason to proceed under the assumption that the account of argument and argumentation which has been developed in the first four parts of this paper is more or less correct.

Before we can turn to the application of the forgoing discussion to Craig's kalam cosmological arguments, we need to say something about that argument, and about the main kinds of discussions which have taken place around it.

\footnotetext{
${ }^{7}$ Perhaps this overstates matters a bit. For example, it might be that there are non-combative uses for arguments — or, at any rate, derivations - in attempts to exhibit justificatory structures in given collections of beliefs, etc. However, what seems clear is that Craig wants to put his kalam cosmological argument to a combative use-and, there, the standard for success is the one which I have described.
} 
The argument which Craig calls "the kalam cosmological argument” goes like this:

1. Every being which begins to exist has a cause for its beginning to exist.

2. The physical universe is a being which begins to exist.

3. (Therefore) The physical universe has a cause for its beginning to exist.

Since the argument is plainly valid, most attention has focussed on the truth of the premises.

Craig claims that 1 . is obviously true, and that throughout history most people have supposed that 1 . is obviously true. Sometimes, he seems to suggest that 1 . might be supported by appeal to the Principle of Sufficient Reason; often enough, though, he seems prepared to say that there isn't really anything else which is needed in order to support a claim whose truth is simply blindingly obvious.

Craig thinks that 2. is also pretty obviously true. If pressed, he has three arguments-one a posteriori and two a priori- to wheel out in support of this premise. Of these arguments, the one which seems to be most important to him is the a posteriori argument, i.e. the argument based on physical evidence that the observable physical universe has a finite past. While there are physicists who contest the standing of Big Bang models, there is a pretty widespread expert consensus that the observable physical universe has a finite past—and that might well seem to give very impressive support to premise 2 .

Craig's opponents have disputed both of the premises. Mackie, Grunbaum, Smith and $\mathrm{I}^{8}$ - among many others - have taken issue with the first premise: why should it be supposed that absolutely everything which begins to exist has a cause for its beginning to exist? And Grunbaum and $\mathrm{I}^{9}$ - among others - have taken issue with the second premise: given the natural interpretation of "begins to exist", it can be questioned whether it is true that a universe which is open in the past—as Big Bang models standardly are—can truly be said to begin to exist. Of course, Craig's opponents have also developed other kinds of criticisms of Craig's argument: in particular, many critics has emphasised the huge gap between the conclusion that the observable physical universe has a cause of its beginning to exist and the claim that the observable physical universe was created by God. However, that criticism - and others like it - is not a criticism of the success of the argument, but rather of the further use to which Craig wants to put the argument on the assumption that it is successful. (Mackie, Smith and $\mathrm{I}^{10}$ —among many others—have also extensively criticised the a priori arguments which Craig gives in support of 2. However, following the stipulation of section 2, I shall just note here that those are different arguments, i.e. they are not the kalam cosmological argument which Craig champions.)

Rather than directly pursue any of these previous discussion, I want to take a slightly different tack. Given the material of the preceding sections of this paper, let us take up

\footnotetext{
${ }^{8}$ Mackie (1982), Grunbaum (1990) (1991) (1994) (1996) (2000) (forthcoming), Smith (1988) (1991) (1993a) (1993b) (1993c) , Oppy (1991) (1995b) (1996)

${ }^{9}$ Grunbaum (1990) (1991) (1994) (1996) (2000) (forthcoming), Oppy (1996) (2001)

${ }^{10}$ Mackie (1982), Smith (1987), Oppy (1991) (1995a) (1995c) (1996)
} 
the question whether Craig's kalam cosmological argument - the argument given at the beginning of the present section of this paper-is a successful argument. In order to answer this question, we need to know what reasonable people who do not accept the conclusion of the argument typically believe; and, in particular, we need to know what reasonable people who reject the argument typically believe. Here, I believe that I can speak with some authority: reasonable people who do not believe that the physical universe has a cause for its beginning to exist typically do not believe that every being which begins to exist has a cause for its beginning to exist. Similarly, it is I think typical for non-theists to fail to believe that every being which begins to exist has a cause for its beginning to exist. Since these observations which I have just made are common knowledge, it follows pretty well immediately that the kalam cosmological argument given at the beginning of this section is not successful: before the argument is propounded, we know that those who do not yet accept the conclusion will almost certainly not accept the premise (even after it is propounded). Remember: if it is claimed that those who reject the premise are thereby shown to be irrational, then it is pointless to claim that the argument is successful; but, if the rationality of those to whom the argument is directed is conceded, then there is no reason not to draw the conclusion that the argument is simply a failure.

Of course, this is not to say that there is not a successful argument to be produced by developing Craig's kalam argument, replacing one or both of the premises with further premises which belong to successful arguments having the initial premises as conclusions. That is, it might be that there are successful arguments $\mathrm{P}_{1}, \ldots, \mathrm{P}_{\mathrm{n}}$ therefore 1 . and $\mathrm{Q}_{1}, \ldots \mathrm{Q}_{\mathrm{m}}$ therefore 2 . If so, then the argument $\mathrm{P}_{1}, \ldots, \mathrm{P}_{\mathrm{n}}, \mathrm{Q}_{1}, \ldots, \mathrm{Q}_{\mathrm{m}}$ therefore 3. will be a successful argument. However, it is crucially important to note that even if this new argument is successful, it still remains the case that the argument with which we began is not successful. Moreover, it is equally important to note that each of the new subsidiary arguments must meet the same stringent standards as we set for the original argument: if those who do not already accept 3. typically do not accept at least one of the $\mathrm{P}_{\mathrm{i}}$ or $\mathrm{Q}_{\mathrm{k}}$, then the new argument will be no more successful than was the original argument. If, for example, the $\mathrm{P}_{\mathrm{i}}$ and $\mathrm{Q}_{\mathrm{k}}$ contain many highly controversial metaphysical claims - as, for example, do Craig's subsidiary a priori arguments for 2.- - then it is immediately obvious that the new argument is not going to be any more successful than was the old argument. (This, of course, is the reason why I have taken pains in previous publications to highlight the controversial metaphysical claims - e.g. about potential infinities, tensed time, and non-logical metaphysical necessity — which serve as further premises in Craig's subsidiary arguments. Given the highly plausible claim that those who do not already accept the conclusion of the argument typically do not accept the conjunction of these controversial claims, it follows directly that those further arguments are no good.)

Even if my argument to this point is accepted, I imagine that the importance of the conclusion of the argument might be contested. True enough, it might be said, there is a sense in which the kalam cosmological argument—and, indeed, all of the subsidiary kalam cosmological arguments developed thus far-are not successful. But most of the literature about Craig's kalam cosmological argument has not been concerned with whether or not the argument is successful in this sense. Rather, most of the literature has 
been a debate about the truth—or perhaps acceptability—of the premises which feature in the kalam cosmological argument and in the subsidiary arguments. And, despite what has been said above, it is far from obvious that Craig always has the worse of these debates.

I agree absolutely! Much of the literature is indeed about questions other than the success of the kalam cosmological argument (and the subsidiary arguments). Moreover, it is only a failure to keep clear about this fact which has allowed Craig to go on insisting that the argument from 1. and 2. to 3. is a successful argument. After all, once something like the truth of 1 . is being discussed, it is tempting for Craig's opponents to advance arguments of their own for the rejection of 1.- -and then, when Craig manages to find satisfactory replies to those arguments, or even replies which he merely wrongly supposes to be satisfactory, it is not too hard for him to suppose that this somehow vindicates the original argument. But, of course, any such supposition would be the product of gross confusion. As I emphasised in the first four parts of this paper, it is one question whether someone is rationally entitled to a given belief; it is quite a different question whether that person can produce arguments which ought to persuade others to share that belief. Even if Craig's opponents cannot produce a single argument which ought to persuade him to reject either 1. or 2., that fact does nothing at all towards showing that the kalam cosmological argument is a good argument.

Some people may be tempted to think that the point which I am making is that the burden of proof rests with Craig (perhaps because he is the one making a positive existence claim). Nothing could be further from the truth. I share David Lewis' distaste for the idea that philosophers are lawyers, forever concerned to debate who has the burden of demonstrating what. ${ }^{11}$ More importantly, I think that argument about "the burden of proof" are almost universally misbegotten, and involve a confusion of doxastic obligations with argumentative obligations. On the one hand, everyone has the doxastic obligation, qua rational agent, to form and revise beliefs according to the canons of rationality. What the content of those beliefs is matters not at all; the obligation is the same in every case. On the other hand, the argumentative burden of proof falls entirely on the person who advances the argument: if you claim to be able to show that $\mathrm{p}$, then no one else incurs any burden to show to you that the assumptions upon which your argument relies are mistaken. If a serious, reflective, rational agent rejects one or more of your assumptions, then, immediately, you can conclude that either you need a new argument or else you need to give up your attempt to show that $\mathrm{p}$, at least in the case of that interlocutor. (Of course, giving up does not mean that you now have some reason to doubt whether p. Just because we like and value agreement — and with good reasondoes not mean that we should be discomforted when we find what appears to be irresolvable disagreement. As I argued in the first section of this paper, there are reasons for thinking it likely that there will be some such disagreements.)

One final point which be worth noting is that the kinds of considerations which I have been urging here are often put forward by theists when the boot is on the other foot, and

\footnotetext{
${ }^{11}$ See the concluding sentence of Lewis (1993). When Lewis read this paper at the University of Wollongong in 1992, I recall his interpolation of the remark, "What, are we lawyers!", into his presentation.
} 
they are seeking to defend themselves against arguments which purport to establish that God does not exist. So-famously - in the context of discussion of evidential arguments from evil, Plantinga makes the point that the observation that non-theists typically find a certain premise in the argument plausible "possesses a certain kind of biographical charm". Although there is some danger of misinterpretation, I think that Plantinga is here endorsing the point that, for the evidential argument from evil to be successful, it has to appeal in its premises to considerations which theists find plausible. But, of course, Craig's remarks on behalf of the first premise of his kalam cosmological argument also "possess a certain kind of biographical charm"12; it's just that, in this case, what is absent is considerations which non-theists find plausible. In general, I think that it is important to discuss all of the arguments for and against the existence of God together; the subject matter of the current paragraph merely provides an instance of the general point. (Perhaps the pressures of specialisation and the lure of the short journal article have helped to conspire to make it seem plausible to suppose that an adequate treatment of one argument—of either kind — can be given in isolation. But the methodological maxim that hypotheses should be assessed in the light of the total relevant evidence applies no less here than it applies anywhere else.) ${ }^{13}$

Finally, then, I am ready to turn to two examples of discussions in which it seems to me that details of Craig's responses to criticisms of his views turns on misunderstandings of the proper framework within which rational argument takes place. The first example (in this section) comes from Craig's response to Grunbaum's allegations about the "presupposition of the spontaneity of nothingness" in the kalam cosmological argument; the second example (in the next section) comes from Craig's response to my defence of Hawking, Davies, and Grunbaum from previous attacks on their claims about the kalam cosmological argument by Craig.

In his response to Grunbaum (2000), Craig (2001:382) writes:

Grunbaum alleges that the kalam cosmological argument ... is predicated, tacitly and insidiously, on the baseless presupposition of the spontaneity of nothingness. Grunbaum commences his critique by simply asking why else one would assume that

\footnotetext{
${ }^{12}$ Plantinga (1979:17)

${ }^{13}$ Suppose-as it seems that Craig would like to think-that it is pretty easy to show that the external cause of the universe has the attributes traditionally ascribed to God, i.e. that there are no further substantive assumptions which need to be made in order to reach this conclusion. That is, from the premises of the kalam cosmological argument plus further uncontroversial assumptions, we can infer that there is an omnipotent, omniscient, perfectly good creator of the world. But there are serious arguments for the conclusion that the existence of such a being is not compatible with the existence of the kinds and amounts of evils which are to be found in the world. So-on the assumption that Craig is right that the other premises are uncontroversial-we have here reasons for denying the conjunction of the premises of the kalam cosmological argument. By Craig's own lights, it seems that it is just a mistake to fail to take these considerations into account when assessing the plausibility of the premises of the kalam cosmological argument. And, of course, there are many similar considerations of this type. Even if Craig thinks that he can accommodate them, by his own lights he is hardly entitled to his snide remarks about the "desperation" of those who refuse to embrace the premises of his favourite argument.
} 
a universe which begins to exist requires an external creative cause at all. 'Is it not because Craig tacitly embraces SoN and uncritically assumes that the externally uncaused natural state of the world is one of nothingness?' Well, no, that cannot be why, since I regard it as patently incoherent to say that the natural state of the world (=universe) is one of nothingness. Rather the reason I believe that 'a universe which begins has an external creative cause' is because that conclusion follows deductively from the truth of the argument's two premises. Presumably, then, Grunbaum in saying that the argument assumes its conclusion, must be alleging that the argument is question-begging. But this is surely not the case. An argument is question-begging if one's only reason for accepting one of its premises is that one already accepts the conclusion. But the evidence for the second premise is clearly independent of the argument's conclusion; and as for the first premise, I and, I daresay, most people believed this premise long before we ever knew that the universe had a beginning or contemplated there being a creative cause of its beginning.

There are various preliminary points to make about the argument in this paragraph.

First, it isn't clear that Grunbaum is charging that the kalam cosmological argument is question-begging. Grunbaum does want to know why anyone would believe that a universe which begins to exist requires an external creative cause. Hence, by implication, it is plausible to suppose that Grunbaum equally wants to know why anyone would believe that each thing which begins to exist requires an external creative cause. (After all, if the universe is one of the things which begins to exist, and there is no good reason to believe that it requires an external cause, then there is no good reason to believe that everything which begins to exist requires an external cause.) This could be construed as a challenge to the acceptability of the first premise, rather than as an allegation that the argument begs the question.

Second, if we agree that Grunbaum's challenge is best construed as an allegation that the kalam cosmological argument is question-begging, it is clear that Craig does not make an adequate response to this allegation, since the argument upon which his response relies is plainly invalid. The argument which Craig provides goes like this: If one's only reason for accepting one of the premises of an argument is that one already accepts its conclusion, then the argument is question-begging. In the kalam cosmological argument, it is not the case that one's only reason for accepting one of the premises of an argument is that one already accepts its conclusion. Therefore the argument is not questionbegging. This argument is plainly invalid: denying the antecedent of an accepted conditional does not give you a reason to accept the denial of the consequent of that conditional.

Third, if we suppose that Craig is here guilty of a minor slip — which many others have made from time to time ${ }^{14}$ —and written "if" when he meant "iff", we save the validity of Craig's argument at the cost of leaving it with a manifestly absurd premise. The suggestion is that we provide the following analysis: an argument is question-begging iff one's only reason for accepting one of the premises of an argument is that one already

\footnotetext{
${ }^{14}$ In the next section, I shall mention one occasion when Craig picked me up for a similar slip!
} 
accepts its conclusion. But, to take the simplest case, consider the argument: "God exists, therefore God exists”. Craig certainly does NOT think that his only reason for accepting the premise of this argument is that he already accepts the conclusion-he takes it that he has numerous independent reasons for accepting that premise-and yet it is clear that this argument is question-begging, if any argument is. Moreover, if we consider the conditional with which Craig began-i.e. the claim an argument is question-begging if one's only reason for accepting one of the premises of an argument is that one already accepts its conclusion-it is plausible to suggest that this conditional is trivially true, because there are no arguments for which it is true that one's only reason for accepting one of the premises is that one already accepts its conclusion. No matter who we consider, and no matter which of their beliefs we choose, they will always have many reasons why they believe as they do. Perhaps this is overstating matters a little; perhaps there are some cases in which a person has only one reason for accepting a given claim. ${ }^{15}$ However, it is in any case manifestly absurd to suppose that Grunbaum is claiming that the only reason there is for believing that everything which begins to exist has an external creative cause is that the universe has an external creative cause. Since it seems perfectly possible for it to be the case that the universe has an external creative cause and yet for it not to be the case that some of the things which begin to exist within the universe have an external creative cause, the claim that the universe has an external creative cause is not any kind of reason for believing that everything which begins to exist has an external cause.

Fourth, Craig claims that he believed the first premise of the argument-i.e. the claim that everything which begins to exist has an external creative cause-_"long before we ever knew that the universe had a beginning or contemplated there being a creative cause of its beginning”. This seems doubtful, even setting aside the (frivolous) point that Craig can't seriously expect us to believe that he is so long-lived! At the very least, it would require some detailed empirical investigation-both historical and sociological-in order to determine whether the belief that absolutely everything which begins to exist has an external cause is pretty much confined to orthodox monotheists who believe that the universe is the product of an external creative agent. Until the data about what is typical of non-theistic belief are in, there is room for serious scepticism about Craig's claim; if non-theists typically do not believe-and have not believed - that everything which begins to exist has an external creative cause, then there is reason for thinking that the premise in Craig's argument is not suitably independent of its conclusion. (Of course, this is not to say that the sole reason for thinking that everything which begins to exist has an external creative cause is that the universe has an external creative cause; rather, it is to suggest that a more plausible analysis of begging the question might bear out the suggestion that the kalam cosmological argument is indeed question-begging.)

Fifth, Craig claims that the reason he believes that 'a universe which begins has an external creative cause' is because that conclusion follows deductively from the truth of the argument's two premises. On a perhaps unsympathetic understanding of this claim,

\footnotetext{
${ }^{15}$ It is hard to know how to properly assess this claim, because it is hard to know how to individuate- and hence to count-reasons. If one has a reason for believing something which is itself supported by a deeper reason, how many reasons does that make for believing the thing in question? Etc.
} 
that cannot be right. The conclusion that God does not exist follows deductively from the truth of certain premises-e.g. (1) that there are unabsorbed evils; and (2) that if there are unabsorbed evils, then God does not exist—but it is nonetheless not the case that Craig believes that God does not exist. A more sympathetic reading would have Craig saying that the reason why he believes that a universe which begins has an external creative cause is because he believes both of the premises of an argument whose validity he recognises and which has the claim as its conclusion. However, even on this more sympathetic reading, I do not think that Craig should be believed. To see why, ask yourself which claim Craig would be more resistant to giving up: the first premise of the kalam cosmological argument or the conclusion of the kalam cosmological argument? On the one hand, the conclusion of the argument is taken by Craig to be a revealed truth; it is a non-negotiable part of his Christian faith. On the other hand, the premise of the argument is merely a deeply held philosophical postulate (which could be given up if, for example, there were sufficient empirical warrant for a physical theory which demanded that it be given up). By his own admission, Craig's reasons for accepting the conclusion of the kalam cosmological argument go beyond any arguments which he could give on its behalf $^{16}$; and-despite his apparent protestations to the contrary-it is surely plausible to think that his enthusiasm for the premise is largely due to this independent attachment to the conclusion of the argument.

Sixth, despite all of the forgoing, there is at least some prima facie plausibility to Craig's initial criticism of Grunbaum. Given that Grunbaum suppose that Craig's belief [that a universe which begins to exist requires an external creative cause] must draw on a tacit presupposition about the spontaneity of nothingness, and given that this presupposition is taken to amount to the claim that the externally uncaused natural state of the world is one of nothingness, there is clearly some reason to say that the alleged presupposition is incoherent, and hence cannot be something upon which Craig relies. After all, it surely does appear incoherent to say that nothingness is a state of some particular thing: taken literally, this seems to require commitment both the existence and the non-existence of the thing in question. However, it is tempting to respond-on Grunbaum's behalf-that the difficulties here are merely verbal: what Grunbaum is after is some justification for the assumption that it is always the existence-rather than the non-existence-of particular things which is in need of explanation. Why shouldn't we think: (i) that, if there were no universe, that would be something which would require explanation; and (ii) that there being a universe is not something which requires explanation. (Of course, if there were no universe, there would be no one around to demand or give the explanation; but that is not inconsistent with the claim that there be an explanation.) Perhaps it is wrong to say that Craig's belief relies on a presupposition about the answer to these questions; but it is not obviously incoherent to suppose that some such presupposition is present.

Suppose we set all of the forgoing objections aside. Given the discussion in the previous parts of this paper, it should be clear that there is still good reason for thinking that Craig's response to Grunbaum is inadequate. However, in order to make this clear, we need to separate out more clearly than Grunbaum does two different aspects of his

\footnotetext{
${ }^{16}$ See Section 8 below for justification of this claim.
} 
challenge to Craig. Remember that Craig is the one who is putting forward the argument: he is the one who claims that the kalam cosmological argument is a good argument for its conclusion. Consequently, if we interpret Grunbaum's remarks as a demand for a reason why he (Grunbaum) should accept the first premise of the argument, then it is nothing to the point to observe - as Craig does - that he (Craig) believes it. (Nor is it anything to the point to observe that many other people believe it, particularly if it is plausible to suppose that those other people typically accept the conclusion of the argument on independent grounds.) Since Craig is the one who is putting forward the argument, it is up to Craig to provide Grunbaum with a reason to accept the first premise of the argument, given that Grunbaum does not accept it as things stand. When Grunbaum says: "Why else would one assume that a universe which begins to exist requires a creative cause [i.e. apart from assuming the spontaneity of nothingness]?” we can interpret Grunbaum as giving expression to the thought that, by his (Grunbaum's) lights nothing less than the assumption of the spontaneity of nothingness would give him (Grunbaum) a reason to accept that premise. Even if we have some reason to doubt that that assumption would give Grunbaum a reason to accept that premise, the force of the challenge remains: since non-theists typically share Grunbaum's puzzlement about why the first premise should be believed, it is clear that we are already in a position to conclude that Craig's argument is unsuccessful.

On the other hand, if we interpret Grunbaum's remark as a demand for a reason why Craig should accept the first premise of the argument—and hence interpret Grunbaum as giving expression to the thought that nothing less than the assumption of the spontaneity of nothingness would give Craig a reason to accept that premise - then, on the contrary, it may well be something to the point to observe that Craig, and numerous other theists, have many independent reasons for accepting that premise (none of which have anything at all to do with the spontaneity of nothingness). In particular, as Craig points out in the first footnote to his paper, there are many considerations about Scripture, revelation, and theological tradition which can be marshalled by theists as reasons for accepting the premise. Thus, if we change the topic from the question of the success of the kalam cosmological argument to the question whether Grunbaum has given Craig a reason to give up the first premise, then the remarks which Craig makes take on a far more substantial appearance. (It is interesting that Craig insists that Grunbaum wrongly supposes that the issue is about the truth of the first premise, when in fact the issue is about the success of the argument. I agree with Craig that the key question is about the success of the argument; but the considerations which Craig adduces could only speak successfully to the issue of his right to continue to assent to the premises.) Of course, if I am right about this then, while Craig may win the battle-since it does seem to me to be doubtful that his entitlement to believe the first premise rests on a prior entitlement to believe in the spontaneity of nothingness - it plainly follows that he loses the war: there is no vindication of the kalam cosmological argument in the line which he takes.

In the light of the forgoing discussion, it is interesting to turn to the final set of criticisms of Grunbaum's treatment of the kalam cosmological argument which Craig makes in the paper under discussion. Here, Craig is responding to Grunbaum's claim to find belief in the spontaneity of nothingness at work in Craig's argument that: (1) if the potentiality of 
the universe's existence did not exist, then it is inconceivable that the universe should become actual; (2) if the potentiality of the universe's existence did exist, then the universe must have an external cause to effect its realisation; (3) the universe did become actual; so (4) there must have been an external cause to effect the realisation of the universe. Addressing the third premise of the argument, Grunbaum asks: What reason is there in the temporally unbounded big bang model for claiming that the big bang universe ever 'became actual'? In reply, Grunbaum suggests two reasons: (a) the presupposition of the spontaneity of nothingness; and (b) the question-begging supposition that 'the potentiality of the universe's existence lay in the power of God to create it', a potentiality which then required divine creation to be actualised.

Against (b), Craig responds that the alleged supposition in question is no premise of the argument, but rather the theist's answer to a question to which the atheist has no answer. Against (a), Craig responds that—as near as he can tell—the alleged presupposition can only be the assumption that things cannot come into being without a cause-yet that it just the first premise of the kalam cosmological argument (and hence, presumably, cannot play a question-begging role in the argument). Finally, in answer to Grunbaum's original question-viz. why think that the big bang universe became actual-Craig suggests that the proponent of the kalam cosmological argument presupposes a tensed theory of time. Since Grunbaum adopts a tenseless theory of time, it is hardly surprising that he finds the argument baffling.

As responses to Grunbaum's request to give him (Grunbaum) a reason to accept (3), it is clear that these are all hopeless. Yes, Craig thinks that there is a legitimate question to which the atheist has no answer; but, by Grunbaum's lights, there is no legitimate question to answer. Yes, Craig is happy with the assumption that things cannot come into being without a cause; but we have already seen that Grunbaum can find no reason to accept that assumption either. Finally, if the kalam cosmological argument really did presuppose a tensed theory of time, then that would be a concession that the argument is not successful for a large class of people. True, there might be a replacement argument developed which draws on arguments for tensed theories of time-but that does not gainsay the point that here we would have a major failing in the kalam cosmological argument. (Actually, I see no reason at all to suppose that the kalam cosmological argument assumes a tensed theory of time; but that's another story. ${ }^{17}$ )

On the other hand, as responses to the request to give reasons why Craig accepts (3), the above suggestions make much more sense. The other claims to which Craig advertsabout the need for causes for things to come into being, the prior existence of the potentiality of the universe's existence, tenseless theories of time, etc.-are all things which Craig believes and which (we may suppose) cohere with the other things which he

\footnotetext{
${ }^{17}$ Craig might now prefer an argument which builds in an explicit assumption that time is tensed; but the argument which is written at the beginning of Section 5 of this paper has no such built in assumptions, either implicit or explicit, at least on any ordinary understanding of the words "begins to exist". It is no consequence of tenseless theories of time that one cannot truly say of things that they begin to exist at particular times (e.g. that a person begins to exist some time in the year before birth). Proponents of tenseless theories of time allow that quantifiers can be restricted, and hence can make perfect sense of claims about existence at particular times, or in particular temporal intervals.
} 
believes. But, if what I said earlier in the paper is right, even if these are good responses to the request to give reasons why Craig accepts (3), they are good responses to the wrong request - for, given that it is Craig who is proposing the argument, what is needed is reasons why Grunbaum by his, i.e. Grunbaum's lights, should accept (3) —and those reasons have simply not been forthcoming.

The second example from Craig which I wish to consider comes from Craig (1997). Here, Craig is discussing my criticisms - in Oppy (1995b) — of his previous responses to criticisms of kalam cosmological arguments by Hawking, Davies and Grunbaum. In that earlier paper, I claim — at various points in the body of the main text—-that, in order for critics to make a successful response to Craig's espousal of the kalam cosmological argument, all they need do is to point out that they have been given no good, nonquestion-begging reasons to accept the premises of that argument. Then, in an appendix to the text, I try to soften this claim - in order to avoid the conclusion that it sets a standard for philosophical argumentation which will never be achieved - by insisting that critics must also provide some reason to think that they are not relevantly different from others who do not already accept the conclusion of the argument. I wrote:

I take the intended audience [for Craig's kalam cosmological arguments] to be presumptively rational agnostics and atheists who hold a wide range of physical and metaphysical beliefs. Moreover, I take it that the members of the intended audience are perfectly entitled to draw on these prior physical and metaphysical beliefs in responding to Craig's argument. But then, as I attempted to show in my paper, it seems quite clear that Craig's arguments are not even presumptively rationally compelling: they rely on physical and metaphysical theses which members of the target audience reject. Since I take it that Craig is not unaware of this fact, I find it completely mysterious why he then continues to advance the arguments. (246)

The position sketched in the first four parts of the present paper is clearly nothing more than an extensive elaboration of the position which is taken for granted in my earlier paper; so it will be perfectly proper to consider whether any of the objections which Craig raises in his reply to the earlier paper raise difficulties for the project now being undertaken.

Craig's critical discussion focuses on my claim, made in the appendix, that the kalam cosmological argument is not provisionally rationally compelling for its intended audience. In that appendix, I wrote the following:

Some alternative conception of the virtue of arguments is now required. I suppose that it is something like this: an argument is provisionally rationally compelling for its intended audience if it is logically compelling and proceeds from premises to which the intended audience is committed; a provisionally rationally compelling argument for an intended audience us rationally compelling for that audience if it is also true that 
the audience will accept the conclusion of the argument rather than give up one of the premises without violating any of the canons of rationality. (245)

As Craig points out, my intention here was to provide an analysis of what it is for an argument to be rationally compelling (for an intended audience); hence, where I wrote “if”, I ought to have written "iff”. Taking this into account, the claim which is put forward is that an argument is provisionally rationally compelling for its intended audience iff it is logically compelling and proceeds from premises to which the intended audience is committed; and that an argument which is provisionally rationally compelling for its intended audience is also rationally compelling for that audience iff it is also true that the audience will accept the conclusion of the argument rather than give up one of the premises without violating any of the canons of rationality.

The first critical point which Craig makes is that the defender of the kalam cosmological argument might reject the analysis. Since the way in which Craig argues at this point is a bit diffuse, I shall need to begin with a fairly lengthy quotation:

Perhaps a member of the audience, like some Soviet philosophers I heard at the World Congress on Philosophy in 1978, stubbornly rejects the premise that the universe began to exist in defiance of and without any counter-explanation of the evidence simply out of a faith commitment to dialectical materialism. He has no adequately warranted defeater of the kalam proponent's evidence for the truth of that premise; is the kalam argument not therefore rationally compelling with respect to him? ... Perhaps Oppy's point is that one's intended audience must be "presumptively reasonable”, so that once the presumption fails, an argument cannot be provisionally rationally compelling for them. But clearly one may regard one's audience as generally reasonable, even if in the case of the premises implying theism they believe irrationally. If they are generally reasonable people, but refuse to believe some of one's premises despite their want of a suitable defeater, then it seems to me that one can legitimately claim “dialectical success”. Dialectical success cannot be equated with convincing one's opponent (or even forcing him to revise his beliefs); after all, many will simply refuse to be convinced. All sorts of psychological and spiritual factors come into play here for which a philosopher cannot be held responsible. Dialectical success in natural theology cannot, then, be measured merely in terms of success in convincing unbelievers. Christian apologist E. J. Carnell pointed out that one of the purposes of apologetics is to remove from the unbeliever any just excuse for his not repenting before God. That objective is achieved so long as the unbeliever is presented sound theistic arguments with substantiated premises for which he has no adequately warranted defeater, even if he refuses to believe those premises.

There are many things to say here.

(1) Granted, it could be that you are arguing with someone who has no reason for their rejection of one of the premises of your argument. However, their inability or refusal to produce a "counter-explanation" need not be even prima facie evidence that they lack such reason. Reasonableness in belief is one thing; warrant in belief is a second thing; 
and skill in debate is a third. Consider the case of the Soviet philosophers whom Craig mentions: if those philosophers were reasonable in their acceptance of dialectical materialism, then it is not impossible that they were reasonable in rejecting the claim that the universe began to exist. And, if those philosophers were not reasonable in their acceptance of dialectical materialism, then there can hardly be any point in trying to argue with them about beliefs which are "infected” by their belief in dialectical materialism.

(2) Granted, people can be generally rational, and yet have "rationality blindspots". However, I can't see any reason to think that arguments which deal with a subject matter with respect to which someone is not rational can legitimately be said to be "dialectically effective" against these people. If they're not rational (with respect to the given subject matter), no argument can be effective against them; but how is one to determine what arguments they would accept if they were rational (with respect to the subject matter at hand) ${ }^{18}$

(3) Granted, dialectical success cannot be equated with convincing one's opponentsand, of course, I have nowhere said that it is. Rather, dialectical success equates with convincing one's reasonable opponents - and important and interesting dialectical success equates with convincing one's reasonable, informed and reflective opponents. Even if I were wrong about the nature of non-theistic belief at large, the fact that Craig's reasonable, informed and reflective philosophical opponents-Smith, Mackie, Grunbaum, et. al.-reject the argument is more or less a proof that the argument is not an important and interesting dialectical success.

(4) It is very hard to see how one could think that the kalam cosmological argument-and its ilk- "remove from the unbeliever any just excuse for his not repenting before God". True enough, by the theist's lights — or, at any rate, by the lights of those theists who accept these arguments - there are valid arguments for the conclusion that God exists with premises all of which theists have good reasons for believing and which are such that non-theists have been unable to find reasons which ought to bring reasonable theists to give them up. But so what? By the lights of non-theists, there are perfectly good reasons not to accept at least some of the premises in question.

(5) The two alternative analyses which Craig canvasses-viz. (A) an argument is provisionally rationally compelling for its intended audience iff it is logically compelling and proceeds from premises which its intended audience ought to accept; and (B) an argument is provisionally rationally compelling for its intended audience iff it is logically compelling and proceeds from premises which are warranted for its intended audience

\footnotetext{
${ }^{18}$ Of course, Craig could just say: (1) Non-theists are ipso facto irrational in their non-theism; and (2) If non-theists were rational, they would accept the kalam cosmological argument as a successful argument for its conclusion. But, by Craig's lights — under the current hypothesis—if non-theists were rational, they would already accept the conclusion of the argument. So what reason could there be for anyone to say that the argument is successful, as opposed to merely sound? Perhaps it is useful to think about arguments concerning sceptical hypotheses at this point: very few people think that there are arguments which ought to persuade sceptics to give up their scepticism, because attempted arguments of this kind inevitably make assumptions which sceptics would not accept.
} 
(i.e. such that members of that audience will accept them if their cognitive faculties are functioning propertly) - plainly won't do. For, given any putative truths, it is all too easy to construct arguments which one takes to satisfy these analyses. Consider, again, the argument: "Either 2+2=5 or God exists; It is not the case that 2+2=5; so God exists". Plainly, by Craig's lights, everyone ought to believe both premises; and, by Craig's lights, anyone whose cognitive faculties are functioning properly will accept both premises. But it is absurd to suppose that this argument is provisionally rationally compelling. (I think that these suggested analyses also go wrong because they are too externalist - there need be no way in which a rational person can tell that the premises of the argument have the status in question. However, I have said more than enough about these matters in the earlier sections of this paper.)

The second critical point which Craig makes is that the defender of the kalam cosmological argument might claim that the kalam cosmological argument meets the standards required in the analysis. Against my claim that the kalam cosmological argument relies on physical and metaphysical theses which members of the target audience reject, Craig says:

Atheism does not imply the contradictory of either of the premises of the argument taken separately. The unbeliever may simply have never realised the implication of the conjunction of these premises Presented with the argument, he may be persuaded to become a theist. Or again, he may not accept one of the premises, but if the theist can furnish him an argument for that premise based on propositions he accepts, or if the theist can furnish a defeater for the defeater which the unbeliever has brought against the premise, then the non-theist may change his mind and come to accept the premise. Is this mere speculation on my part? Not at all; I (and others) have seen atheists and agnostics change their minds when presented with the kalam cosmological argument and become theists. Thus, hard empirical evidence refutes Oppy's claim that the kalam cosmological argument is a dialectical failure.

There are several things to say here.

(1). Granted, it is not logically impossible for there to be an unbeliever who had never realised the implication of the conjunction of the premises of the argument. Granted again, it is not logically impossible for there to be an unbeliever of this kind who is persuaded to become a theist when presented with the argument. But, of course, exactly the same can be said about the argument: "Either God exists or $2+2=5$. It is not the case that $2+2=5$. So God exists.” Argument which achieve this standard are easy to come by. But once we set our sights higher-and consider realistic cases of reasonable nonbelievers - it is plausible to think that there just will not be any such people. (Note, in particular, that the premises are both quite sophisticated, while the inference is as easy as can be. How likely is it that someone with the sophistication to understand the premises would miss the inference?)

(2). Granted, if a non-believer rejects one of the premises of the argument, it is open to the proponent of the argument to come up with a new argument (for that premise, and 
hence for the original conclusion). But, in that case, it is the new argument which is successful — no credit is passed on to the original argument.

(3) Since the unbeliever has no obligation to furnish the theist with a defeater for one or other of the premises of the argument-and, indeed, since the furnishing of such defeaters is a logically distinct task from that of justifiably refusing to accept a premise in an argument which is brought against one-there is no prospect of achieving a change of mind by “defeating a non-theist's defeater".

(4) It is laughable to suppose that there is "hard evidence" that the kalam cosmological argument has been dialectically effective in actual cases. Sure, there may have been cases of "atheists and agnostics who changed their minds when presented with the kalam cosmological argument"-but, at the very best, this is no more than prima facie evidence for the dialectical efficacy of the argument. It is notoriously hard to make good inferences to causally efficacious properties, particularly in cases where there are small sample sizes and no proper controls. A little thought about the likely circumstances in which this socalled "hard evidence" was obtained will surely suggest other more plausible explanations for the change in belief, i.e. explanations which do not claim that it was the argumentative credentials of the argument which played the crucial causal role. In particular, the character and status of the presenter of the argument, the state of the person to whom the argument is presented, and the likely circumstances of the presentation of the argument ought not to be overlooked. (Of course we might also ask questions about the rationality of the people in question, about the nature of their alleged atheism, and so forth. And one might point to numerous similar cases with theists and presentations of, say, evidential arguments from evil. But, as I said, the claim is really laughable, so there is no point in pursuing these thoughts further.)

(5) Even if Craig's replies were more telling, there just is no getting away form the fact that non-believers typically do not suppose that the universe has an external cause, and nor do they typically suppose that everything which begins to exist has a cause of its beginning to exist. Granted, I haven't done all of the empirical work which would be required to fully justify this claim — but the non-theist literature is surely ample testimony to the point.

The third critical point which Craig makes is that, even if I were right that the kalam cosmological argument is not rationally compelling - in the sense of my analysis - that point would have no philosophical significance. According to Craig, even if the argument is not rationally compelling, it

may still be sound and provide warrant for theistic belief. It would just not be very useful in evangelism. Perhaps Oppy's conclusion has the practical implication that the Church should not waste her time and resources holding training sessions on how to use the kalam cosmological argument to win souls. That would be an important lesson in stewardship and missions for which we might thank Oppy; but it is not a conclusion of interest to philosophers. 
But, on the one hand, sound arguments for the conclusion of the kalam cosmological argument are a dime a dozen if the conclusion of that argument is true; and, on the other hand, it is surely plain that there is no sense in which the kalam cosmological argument “provides warrant for theistic belief”. Even if it is true that belief in the premises of the argument provides warrant for belief in the conclusion of the argument-and that is something which I have already given reasons to doubt-it does not follow that the kalam cosmological argument is a successful argument for theists. Craig is here failing to separate considerations which concern rational or warranted belief from considerations which concern argumentation-cf. the discussion in earlier parts of the present paper. Who does he here suppose is to obtain additional warrant for their belief in the conclusion of the argument when the argument is presented to them? Since he is conceding, for the sake of argument, that it won't be non-theists, he can only have theists in mind. But - if I am right - those theists who accept the premises of the kalam cosmological argument typically do so because they already accept the conclusion of the argument, i.e. for typical theists who accept the conclusion of the argument-including Craig-it is the conclusion of the argument which provides warrant for the first premise, rather than the other way around.

Apart from criticising the way in which I would like to characterise debate about the success of kalam cosmological argument, Craig offers his own way of understanding what is going on.

The issue before us concerns the role of defeaters of prima facie warranted beliefs. ... In order to remove the warrant provided by the [kalam cosmological] argument for its conclusion, the argument's detractor must either expose a fallacy in its logical inference form or defeat at least one of its premises. Refutatory defeaters brought against the premises may be either rebutting defeaters which aim to show that the relevant premise is false or undercutting defeaters which aim to show that the relevant premise has not been proved to be true. [In the case of undercutting defeaters, the key question is] the comparative warrant enjoyed by the premises and their respective defeaters. If the premise is more strongly warranted than its ostensible defeater, then any informed and rational person will, ceteris paribus, accept the soundness of the argument. The argument's defender will typically seek to decrease the defeater's warrant by defeating it, either rebutting or undercutting it, thereby increasing the relative warrant of the premise under attack. (236)

There are various points to make about this paragraph, and the position which Craig is defending. However, given the preceding discussion, these points can be made very briefly. First, it is isn't true that the kalam cosmological argument-nor even the conjunction of the premises of that argument- "provides warrant" for its conclusion. Second, even if it were true that the kalam cosmological argument "provides warrant" for its conclusion, it would not be incumbent upon opponents of the argument to "remove that warrant”. Third, detractors of the argument have other options - rather than "defeat" at least one of the premises, they can point out that they do not accept one of the premises (and they can also point out that this is typical of those who do not accept the conclusion of the argument). Fourth, it isn't true that what a reasonable person believes depends 
upon the "comparative warrant" enjoyed by premises and defeaters-this thought is the product of confusing doxastic issues with argumentative issues, and also probably fails to respect the sense in which reasons must be accessible to those who have them.

So far, I have only discussed the methodological issues which are raised in Craig (1997). There are many other areas of disagreement with the claims made in Oppy (1995b) which Craig airs in his reply. However, if I am to discuss these further claims, I shall need to do so somewhere else. Any such discussion would go much more smoothly if Craig and I could agree on the issues which have been the subject matter of the present paper. ${ }^{19}$

As a concluding irony, it is perhaps worth noting that there is a sense in which Craig is actually quite sympathetic to the considerations which I have been advancing. For instance, in Craig (1994d) he writes as follows:

The Bible says all men are without excuse. Even those who are given no good reason to believe and many persuasive reasons to disbelieve have no excuse, because the ultimate reason they do not believe is that they have deliberately rejected God's Holy Spirit. ... (37)

[W] must make a distinction between knowing [that Christianity] is true and showing it is true. We know Christianity is true primarily by the self-authenticating witness of God's Spirit. We show Christianity is true by demonstrating that it is systematically consistent. ... But should my arguments seem weak and unconvincing to you, that's my fault, not God's. It only shows I'm a poor apologist, not that the gospel is untrue. ... [U]ltimately, you have to deal, not with argument, but with God himself. ... (48)

[T] he view just expounded enables us to hold to a rational faith which is supported by argument and evidence without our making that argument and evidence the foundation of our faith. It is tremendously liberating to be able to know that our faith is true and to commend it as such to an unbeliever without being dependent upon the vagaries of argument and evidence for the assurance that our faith is true. (49)

These paragraphs suggest - to me at any rate-that Craig is perfectly well aware of the distinctions which I have drawn between reasonable belief revision, warranted belief, and success in argument or debate. Theists can be warranted in their belief even if they are hopeless at debate and argument. Theists can be warranted in their beliefs even if they can adduce no defeaters for the defeaters which non-theists bring against those beliefs (e.g. perhaps, in evidential arguments from evil). Reasonable theists are not required to

\footnotetext{
${ }^{19}$ Of course, if the points which I have made about Craig (1997)(2000) are correct, then similar points can be made about pretty much everything else that Craig has written about kalam cosmological arguments. And similar points can also be made about most other recent defences of arguments for the existence of first causes, designers, ultimate grounds of being, etc. The recent wave of enthusiasm for traditional arguments for the existence of these things seems to me to be mired in the same confusions which I claim to find in Craig's discussions of kalam cosmological arguments. Again, however, I cannot hope to provide a defence of this further claim here.
} 
give up their beliefs merely because non-theists raise questions to which they can give no decent answers (e.g., perhaps, about the excruciating suffering of animals and young children, or the hiddeness of God, or the inconsistencies and absurdities of scripture, or the unintelligibility of libertarian freedom, or whatever).

It would be nice to think that I am not being too optimistic in supposing that pointing this out has some chance of leading Craig to be more concessive about the weakness of the kalam cosmological argument, and about the possibility that there are reasonable nontheists. Of course, given that one is an externalist about warrant-as Craig surely isthere is nothing in any of this to suggest that Craig is obliged to concede that there can be non-theists whose non-theism is warranted; but, of course, if we are externalists about warrant, then these is surely no prospect that theists and non-theists will agree about where warrant lies. Nevertheless, even if we are externalists about warrant, there is still the possibility of some measure of understanding — of knowing what it's like to be one of - those who fall on the other side of the great divide. And that, it seems to me, is an outcome to be welcomed.

\section{References}

Craig, W. (1979) The Kalam Cosmological Argument London: Macmillan

Craig, W. (1985) "Professor Mackie and the Kalam Cosmological Argument" Religious Studies 20, 367-75

Craig, W. (1988) “Quentin Smith on Infinity and the Past” Philosophy of Science 55, 453-5

Craig, W. (1991a) “Time and Infinity” International Philosophical Quarterly 31, 4, 387401

Craig, W. (1991b) “Theism and Big Bang Cosmology” Australasian Journal of Philosophy 69, 4, 492-503

Craig, W. (1992a) "The Origin and Creation of the Universe: A Reply to Adolf Grunbaum” British Journal for Philosophy of Science 41, 473-91

Craig, W. (1992b) "God and the Initial Singularity” Faith and Philosophy 9, 238-48

Craig, W. (1993a) "Graham Oppy and the Kalam Cosmological Argument” Sophia 32, 111

Craig, W. (1993b) “The Caused Beginning of the Universe” British Journal for Philosophy of Science 44,

Craig, W. (1994a) "Prof. Grunbaum on Creation” Erkenntnis 40, 325-41

Craig, W. (1994b) “Creation and Big Bang Cosmology” Philosophia Naturalis 31, 217-24

Craig, W. (1994c) “A Response to Grunbaum on Creation and Big Bang Cosmology” Philosophia Naturalis 31, 237-49

Craig, W. (1994d) Reasonable Faith, rev. ed., Wheaten, Ill: Crossway

Craig, W. (1997) "In Defence of the Kalam Cosmological Argument” Faith and Philosophy 14, 236-47

Grunbaum, A. (1990) “The Pseudo-Problem of Creation in Physical Cosmology” in J. Leslie (ed.) Physical Cosmology and Philosophy New York: Macmillan, 92-112

Grunbaum, A. (1991) "Creation as a Pseudo-Explanation in Current Physical Cosmology” Erkenntnis 35, 233-54 
Grunbaum, A. (1994) "Some Comments on William Craig’s 'Creation and Big Bang Cosmology"” Philosophia Naturalis 31, 225-36

Grunbaum, A. (1996) "Theological Misinterpretations of Current Physical Cosmology" Foundations of Physics 26, 4, 523-43

Grunbaum, A. (2000) "A New Critique of Theological Interpretations of Physical Cosmology" British Journal for Philosophy of Science 51, 1-43

Grunbaum, A. (forthcoming) "The Poverty of Theistic Cosmology”, ms.

Lewis, D. (1993) “Evil for Freedom’s Sake” Philosophical Papers 22, 149-72

Mackie, J. (1982) The Miracle of Theism Oxford: Clarendon

Oppy, G. (1991) "Craig, Mackie, and the Kalam Cosmological Argument” Religious Studies 27, 189-97

Oppy, G. (1995a) “Kalam Cosmological Arguments: Reply to Professor Craig” Sophia 34, 2, 15-29

Oppy, G. (1995b) "Professor William Craig’s Criticisms of Critiques of Kalam Cosmological Arguments by Paul Davies, Stephen Hawking, and Adolf Grunbuam” Faith and Philosophy 12, 2, 237-50

Oppy, G. (1995c) "Reply to Craig: Inverse Operations with Transfinite Numbers and the Kalam Cosmological Argument” International Philosophical Quarterly 35, 2, 219-221

Oppy, G. (1996) "Review of W. Craig and Q. Smith Theism, Atheism, and Big Bang Cosmology Oxford: Clarendon” Faith and Philosophy 13, 1, 125-133

Oppy, G. (2001) "Time, Successive Addition and Kalam Cosmological Arguments" Philosophia Christi 3, 1, 181-91

Plantinga, A. (1979) “The Probabilistic Argument from Evil” Philosophical Studies 35, $1-53$

Smith, Q. (1987) “Infinity and the Past” Philosophy of Science 54, 63-75

Smith, Q. (1988) “The Uncaused Beginning of the Universe” Philosophy of Science 55, 39-57

Smith, Q. (1991) “Atheism, Theism and Big Bang Cosmology” Australasian Journal of Philosophy 69, 1, 48-65

Smith, Q. (1993a) “The Wave Function of a Godless Universe” in W. Craig and Q. Smith Theism, Atheism, and Big Bang Cosmology Oxford: Clarendon, 301-337

Smith, Q. (1993b) “Did the Big Bang have a Cause?” British Journal for Philosophy of Science

Smith, Q. (1993c) “A Defence of the Cosmological Argument for God's Non-Existence” in W. Craig and Q. Smith Theism, Atheism, and Big Bang Cosmology Oxford:

Clarendon, 232-255 